\title{
XAMANISMO E CRISTIANISMO ENTRE OS AKWẼ-XERENTE $(\mathrm{TO})^{1}$
}

\author{
Valéria Moreira Coelho de Melo ${ }^{2}$
}

Resumo: O presente texto é resultado de pesquisa realizada entre os Akwẽ-Xerente, povo indígena falante de língua Jê e habitante do estado do Tocantins. À luz de dados etnográficos e do diálogo com trabalhos que abordam a temática do xamanismo indígena na antropologia, propõe uma reflexão a respeito de reelaborações do xamanismo akwẽ no contexto da relação estabelecida com o cristianismo. A discussão vai ao encontro de abordagens que pensam a mudança enquanto parte da dinâmica de transformações que, como esses estudos mostram, é própria do xamanismo e das sociocosmologias indígenas das Terras Baixas da América do Sul, de maneira mais ampla.

Palavras-chave: Akwẽ-Xerente. Xamanismo. Cristianismo.

\section{SHAMANISM AND CHRISTIANITY AMONG THE AKWẼ-XERENTE (TO)}

Abstract: This text is the result of research conducted among the Akwẽ-Xerente, Jê-speakers and inhabitants of the state of Tocantins. Based on ethnographic data and dialogue with works on the subject of indigenous shamanism in anthropology, it proposes a reflection on new meanings of akwẽ shamanism in the context of the relationship established with Christianity. The discussion is about the change as part of the dynamics of transformations, as these studies show, is characteristic of indigenous shamanism and sociocosmologies of the South America Lowlands.

Keyword: Akwẽ-Xerente. Shamanism. Christianity.

\section{CHAMANISME ET CHRISTIANITÉ PARMI LES AKWẼ-XERENTE (TO)}

Résumé: Ce texte est le résultat d'une recherche menée auprès des Akwẽ-Xerente, des peuples autochtones parlant la langue Jê et des habitants de l'État de Tocantins. À la lumière des données ethnographiques et du dialogue avec des œuvres qui abordent le thème du chamanisme indigène en anthropologie, il propose une réflexion sur les réélaborations du chamanisme akwẽ dans le contexte de la relation établie avec le christianisme. La discussion rencontre des approches qui considèrent le changement comme faisant partie de la dynamique des transformations qui, comme le montrent ces études, sont caractéristiques du chamanisme et des sociocosmologies indigènes des basses terres d'Amérique du Sud, d'une manière plus large.

Mots-clés: Akwẽ-Xerente. Chamanisme. Christianisme.

\section{CHAMANISMO Y CRISTIANISMO ENTRE EL AKWẼ-XERENTE (TO)}

Resumen: Este texto es el resultado de una investigación realizada entre los Akwẽ-Xerente, indígenas que hablan el idioma Jê y habitantes del estado de Tocantins. A la luz de los datos etnográficos y el diálogo con obras que abordan el tema del chamanismo indígena en antropología, propone una reflexión sobre las reelaboraciones del chamanismo akwẽ en el contexto de la relación establecida con el cristianismo. La discusión se encuentra con enfoques que piensan en el cambio como parte de la dinámica de las transformaciones que, como

\footnotetext{
1 A discussão presente no presente texto é parte das reflexões desenvolvidas na tese de doutorado intitulada "O movimento do mundo. Cosmologia, alteração e xamanismo entre os Akwẽ-Xerente", defendida em 2016.

${ }^{2}$ Graduada em História pela Universidade Federal do Tocantins (UFT), Doutora em Antropologia Social pela Universidade Federal do Amazonas (UFAM), professora da Faculdade de História da Universidade Federal do Sul e Sudeste do Pará (Unifesspa).
}

Revista Escritas do Tempo - v. 1, n. 3, nov/2019-fev/2020 - p. 177-200 
muestran estos estudios, son características del chamanismo y las sociocosmologías indígenas de las tierras bajas de América del Sur, de una manera más amplia.

Palabras-clave: Akwẽ-Xerente. Chamanismo. Cristianismo.

Bdâ (sol) e Wairê (lua) são heróis míticos frequentemente evocados nas narrativas contadas entre os Akwẽ. Akwẽ é a maneira como o povo indígena também conhecido como Xerente se autodenomina. Com uma população de aproximadamente 3.500 pessoas $^{3}$, os Akwẽ-Xerente habitam aldeias distribuídas nas Terras Indígenas Xerente e Funil e estão muito presentes também nas cidades de Tocantínia e Miracema, no estado do Tocantins. São falantes da língua akwẽ, pertencente a tronco linguístico Macro-Jê.

Os Xerente e os outros Jê são marcados pelo dualismo que estrutura o universo sociocosmológico a partir de sua divisão em uma multiplicidade de metades. Entre os Akwẽ, o traço e o círculo que compõem a base da pintura corporal identificam as pessoas enquanto pertencentes às metades Wahirê e Doí. Cada uma dessas metades, por sua vez, subdivide-se em três clãs. A metade Doí inclui os clãs: kuzãa, kubazi e kritó; e a metade Wahirê: krozaké, kreprehí e wahirê. As metades são patrilineares e exogâmicas.

O contato dos Xerente com a sociedade não indígena remonta ao século XVIII, quando, impulsionadas pela busca de ouro, expedições mineradoras passaram a percorrer a região dos rios Araguaia e Tocantins (GIRALDIN, 2004; SCHROEDER, 2006). Até pelo menos meados do século XIX, combatendo a invasão do seu território tradicional, os Akwẽ estabeleceram uma relação extremamente conflituosa com os não indígenas. Em 1850 foram aldeados pelos freis capuchinhos Raphael de Taggia e Antônio de Ganges, em Tereza Cristina ${ }^{4}$ (GIRALDIN; SILVA, 2002). Com os missionários católicos tiveram início as experiências de catequese e escolarização entre o grupo.

Grigório (2014) chama atenção, entretanto, para o fato de que apesar dos missionários católicos serem percussores da pregação do evangelho entre os Akwẽ, poucos deles se consideram atualmente como católicos. Para a autora, isso se deve, sobretudo, a intensa atuação da Missão Batista que, iniciada por volta 1936, consolidouse entre os Akwẽ em 1950. A despeito da atuação mais antiga dos Batista, observa-se entre os Xerente também a presença de missionários de outras denominações.

\footnotetext{
${ }^{3}$ Dados do Instituto Socioambiental, https://pib.socioambiental.org/pt/Povo:Xerente. Acesso em: 10 jan. 2020.

${ }^{4}$ Lugar que em 1851 passou a se chamar Piabanhas e hoje corresponde a cidade de Tocantínia-TO.
} 
Com as trocas estabelecidas a partir do contato, o entendimento da religiosidade e também da medicina não-indígena se deu a partir dos dispositivos da cosmovisão do grupo. A exemplo disso, Jesus Cristo passou a ser associado à Bdâ, que também é chamado de Waptokwa. A Virgem Maria passou a ser associada a Wazeparkwá (mãe de Waptokwa) e São Pedro (companheiro bíblico de Jesus) associado à Waire (Mattos, 2009). Os santos da umbanda e o Espírito Santo parecem ser entendidos, por sua vez, a partir da ideia dos espíritos denominados tdekwa ("Dono"), que na cosmologia akwẽ são aqueles responsáveis pela proteção de diferentes recursos naturais e responsáveis pela formação e pelo poder dos sekwa. Neste texto, pela falta de espaço, a análise será direcionada apenas para as associações feitas a partir do acesso ao cristianismo.

Os sekwa são os xamãs ${ }^{5}$ Xerente. Eles são sujeitos descritos como possuidores de capacidade visual e auditiva extraordinárias e sonhos povoados por espíritos. São descritos ainda como pessoas que não têm uma vida longa. No passado, os sekwa eram figuras centrais nos principais rituais, nas disputas entre clãs e naquelas com outros povos (NIMUENDAJÚ, 1942; MAYBURY-LEWIS, 1990; MORAIS-NETO, 2007). Entre os Xerente, eles são os responsáveis tradicionais pela mediação entre o mundo humano e não-humano e, portanto, daquilo que extrapola as fronteiras do grupo. Neste sentido, como procurei mostrar em outro momento (MELO, 2016), os sekwa podem ser pensados como metáfora da forma como os Akwẽ parecem se relacionar com o exterior.

O contato, o cessar das atividades bélicas e a retração da vida ritual fizeram com que o xamanismo akwẽ ganhasse novos contornos ao longo do tempo. A recorrência de narrativas que restringem a atuação dos sekwa aos processos terapêuticos e à feitiçaria é exemplo nesse sentido. No presente texto, chamando atenção para alguns aspectos da relação estabelecida pelos Akwẽ com religiosidades cristãs, procuro argumentar, entretanto, que, a despeito das mudanças, o xamanismo não perdeu sua ressonância na socialidade $a k w \tilde{e}$.

Evidencio, a exemplo disso, como algumas apropriações e reelaborações feitas do cristianismo podem ser pensadas a partir de uma lógica própria do xamanismo akwẽ. Nesta perspectiva, a frequente menção dos meus interlocutores ao desaparecimento dos "sekwa de verdade", ou a adoção de aspectos e práticas não indígenas são pensados em

\footnotetext{
${ }^{5}$ De acordo com Langdon (1996, p.12), xamã é uma palavra de origem siberiana e faz alusão a um indivíduo capaz de exercer o papel de "mediador entre o mundo humano e o mundo dos espíritos". A comunicação com agentes sobrenaturais com poderes e conhecimentos tanto para curar quanto para agredir é uma das características fundamentais do xamanismo. Para Viveiros de Castro (1992, p. 36), os xamãs são ainda "formuladores e divulgadores dos saberes cosmológicos".
} 
termos de transformações e deslocamentos ${ }^{6}$. Não são aqui entendidos, portanto, como uma evidência de desarticulação do xamanismo.

A discussão é inspirada pelo debate teórico que tem procurado redimensionar o distanciamento que se estabeleceu entre os povos do Brasil central e aqueles da Amazônia (SOUZA, 2004; GORDON, 2006; EWART, 2013) e por outros trabalhos que defendem que as mudanças historicamente observadas nas práticas xamânicas podem ser pensadas enquanto parte de uma dinâmica pautada na transformação, e que é própria das sociocosmologias indígenas (VILAÇA, 2000; PÉREZ-GIL, 2004). Os dados etnográficos aqui analisados são oriundos de pesquisa realizada entre Akwẽ-Xerente entre os anos de 2012 e $2015^{7}$, sobretudo nas aldeias Salto ${ }^{8}$ e Rio Sono ${ }^{9}$, por meio da observação participante.

No que diz respeito aos estudos que se dedicam a pensar a relação dos povos indígenas com religiosidades cristãs, dentre outros trabalhos, ajuda-nos a pensar os dados que aqui são analisados, os apontamentos de Capiberibe (2017). A autora chama atenção para o fato de que o interesse da antropologia pela temática não é novo e tem inspirado análises, em alguns casos, conflitantes. Para Capiberibe, algo recorrente nessas análises, independente de opções teóricas, é que elas tendem a enfatizar "polaridades dicotômicas, como indivíduo/sociedade, cristianismo/xamanismo, crença/prática, fé/superstição, religião/magia" (2017, p. 312).

A autora alerta, entretanto, que não se pode perder de vista "que os fenômenos sociais não são objetos com contornos perfeitamente definidos" (CAPIBERIBE, 2017, p. 312). Ainda, para ela, "a falta de um modelo monolítico e o reconhecimento que as igrejas dão às mais diferentes formas de religiosidade cristã sustentadas pelos povos nativos fazem pensar que o que se passa é uma espécie de transformação de mão dupla" (CAPIBERIBE, 2017, p. 313).

\footnotetext{
${ }^{6}$ De maneira semelhante ao que propõe Pérez-Gil (2004) para o contexto Yaminawa.

${ }^{7}$ A pesquisa em questão não tinha a análise da relação dos Xerente com o cristianismo como seu objeto principal.

${ }^{8}$ A aldeia Salto fica a mais ou menos $17 \mathrm{~km}$ do perímetro urbano do município de Tocantínia e também não muito distante do rio Tocantins. A proximidade com o perímetro urbano permite tanto o deslocamento frequente dos moradores até a cidade, quanto a visita comum de não-indígenas à aldeia (comerciantes, missionários, pesquisadores, dentre outros). Na época da pesquisa essa aldeia possuía uma população de aproximadamente 350 pessoas.

9 A aldeia Rio Sono, juntamente com a aldeia Porteira, é uma das aldeias Xerente mais antigas. Localizada à margem esquerda do Rio Sono, encontra-se afastada aproximadamente $75 \mathrm{Km}$ da cidade de Tocantínia. Ela e a aldeia Salto estão, portanto, em pontos extremos e opostos da Terra Indígena Xerente. $\mathrm{Na}$ época da pesquisa a população da Aldeia Rio Sono era em torno de 62 pessoas.
} 
Sem ignorar o caráter historicamente assimétrico das relações estabelecidas entre indígenas e não-indígenas no Brasil, na análise que proponho aqui, por meio de aspectos pautados na cosmovisão $a k w \tilde{e}$, opto por pensar as apropriações do cristianismo a partir da agência dos interlocutores da pesquisa. Assim, a despeito da percepção da existência de um xamanismo menos elaborado entre povos falantes de língua Jê (CASTRO, 1986; PISOLATTO, 1996) e para além do número ou da reputação dos sekwa atuais, o que procuro mostrar é como o xamanismo akwẽ é um dos mecanismos responsáveis por capturar e processar a diferença no interior da socialidade.

Portanto, mais do que um conjunto de práticas, o xamanismo é aqui pensado e compreendido, de maneira semelhante ao que ensina Vilaça (2000) para o caso Wari e Pérez-Gil (2004) para o caso dos Yaminawa, como um - marco-sociológico geral, ou ainda, como uma forma de controle do movimento que altera a relação entre as diferentes subjetividades que povoam o cosmo, como propõe Gallois (1996).

\section{Adão, Eva e a cosmovisão akwẽ}

De acordo com narrativas, no começo, Bdâ (sol) andava pela terra e foi ele o criador de tudo. Foi ele quem criou os Akwẽ, deu-lhes nomes pessoais, armas de guerra, músicas, tudo! Bdâ andava sempre na companhia de Wairê (lua), seu companheiro de aventuras. Por vezes aconselhava-se com ele sobre a maneira de lidar com suas criações. Mas, o que tinha Bdâ de inteligente, poderoso e bondoso, Wairê tinha de desastrado e por isso suas intervenções nas criações de Bdâ tiveram sempre consequências desagradáveis para a vida dos Akwẽ. Depois que Bdâ e Wairê prepararam tudo que o povo precisava, eles se mudaram para o céu. Antes, entretanto, reuniram os Akwẽ e se despediram deles em meio a cânticos e discursos.

Após a partida de Bdâ e Wairê, os Akwẽ sentiam saudade e por isso sempre havia algum grupo viajando para visitá-los no céu. O percurso da viagem era em direção a leste até chegar ao pé do céu. A viagem era tão longa, que os viajantes chegavam ao destino já envelhecidos, mas Bdâ os orientou que antes de retornarem, eles deveriam se banhar em uma lagoa, o que fazia com que se tornassem jovens novamente ${ }^{10}$. Os

\footnotetext{
${ }^{10}$ Uma das versões a que tive acesso, contada por um Akwẽ evangélico, relata que Waptokwa deu a dois akwẽ que foram visitá-los um côfo com um pouquinho de arroz e dois ovinhos de andorinha, para que os homens se alimentassem durante a viagem de volta. Observando os mantimentos um dos homens reclamou ressentido de Waptokwa ter-lhes dado uma quantidade tão pequena de comida. Entretanto, quando começaram a jornada de volta à aldeia, os cofos se tornaram subitamente repletos e pesados. $\mathrm{O}$ homem que anteriormente reclamava da comida escassa reclamou então do excesso, dizendo que não
} 
viajantes passaram então a proceder de acordo com as orientações recebidas. Em meio às visitas constantes, Bdâ, já um tanto cansado, orientou um grupo que retornava para casa que percorresse o caminho de volta à aldeia sem olhar para trás. Entretanto, tomadas pela curiosidade e pela desobediência, as pessoas que compunham o grupo, logo que colocaram os pés no chão, fizeram exatamente o que lhes havia sido proibido. Neste instante viram o grande mar que desde então foi interposto entre a terra e o pé do céu. Assim teria se estabelecido a separação não só entre o céu e a terra, mas também entre os Akwẽ e seus demiurgos.

Bdâ e Wairê são o sol e a lua vistos como humanos pelos Akwẽ. Assim tomados, eles são tidos como os responsáveis pelas principais invenções que tornaram possível a socialidade. Segundo Nimuendajú (1942), a palavra bdâ substitui também a palavra sdakró, que faz referência à luz solar, ao calor do sol. O sol é às vezes também denominado de Waptokwa (grande pai). De acordo com Mattos (2009), a termo Waptokwa enfatiza o caráter gerador e provedor da figura paterna e por isso seria usado também para fazer referência a pessoas, sobretudo do sexo masculino, que tenham prestado favores importantes ao grupo. Com o contato dos Akwẽ com religiões cristãs, o termo Waptokwá passou a ser utilizado para fazer menção a figura do Deus cristão. Comparações/associações entre Bdã e Cristo também são comuns.

Os heróis míticos Bdã e Wairê aqui apresentados, são referências importantes por meio das quais os Akwẽ pensam a si próprios e a relação estabelecida com aquilo que os cerca. Assim, narrativas envolvendo esses personagens podem nos ajudar a pensar como elementos da mensagem pregada pelos missionários cristãos têm sido elaborados na cosmovisão do grupo.

Pelo contato com os não-índios, Waptokwa (Bdâ) passa a emergir em algumas narrativas sendo associado aos Akwẽ, e às vezes sendo denominado também como Deus ou Jesus. Em contrapartida, Wairê passou a ser relacionado aos brancos e ocasionalmente denominado de Pedro, personagem que ora faz alusão ao apóstolo bíblico, ora parece fundir em si as figuras de Pedro Álvares Cabral e Dom Pedro I. Em Raposo (2009) encontramos um mito, narrado por Constantino Skrawe, elucidativo para nos ajudar a pensar a respeito dessas associações:

seriam capazes de consumir tudo e que teriam dificuldade para carregar. A reflexão do narrador foi que os akwẽ estão sempre reclamando.

Revista Escritas do Tempo - v. 1, n. 3, nov/2019-fev/2020 - p. 177-200 
Depois que Waptokwa deu a Eva pro Adão, diz que foi da costela, ele foi embora. Aí eles comeram a laranja e Eva começou a produzir. Foi produzindo, produzindo... foi muito. Produziu muito e ficou todo mundo nu, a criançada toda. E ele mais a Eva ficaram com vergonha porque Waptokwa tinha avisado pra eles não comer. Passou um tempo e Waptokwa apareceu mais o Pedro. Então eles correram pra vestir as crianças que estavam todas nuas. Só que, como tinha produzido muito, só conseguiu vestir um pouco. E então Adão correu com aqueles que estavam nus pra esconder no mato. Tava com vergonha. Quando Waptokwa chegou mais o Pedro, acharam Eva sozinha com aqueles que tinham colocado a roupa. Waptokwa falou: Mas eu falei que não era pra comer e vocês dois comeram! Disse então que era para o Pedro ficar com a Eva e com as crianças que tinham vestido. Enquanto isso, correu atrás de Adão que já estava escondido no mato com as crianças nuas. E disse: Esses aqui eu é que vou cuidar! Então, o que ficou no mato nu é o Akwe e o que ficou mais o Pedro é o ktâwanõ (branco). (RAPOSO, 2009, p. 97).

A narrativa de Skrawe se diferencia, portanto, daquela que abre esta seção do texto. Skrawe não menciona apenas os Akwe. Ele recorre justamente a elementos da mitologia cristã, para inserir os "brancos" e estabelecer diferenças entre eles e os Akwe. No mito, como chama atenção Raposo (2009), os Akwẽ aparecem relacionados à Waptokwa e ao masculino (Adão). Enquanto isso os brancos são associados à Wairê e ao feminino (Eva). Essa associação entre Wairê e o branco, como enfatiza a autora, não é por acaso. Vale lembrar que Wairê emerge geralmente nas narrativas com responsável por consequências desagradáveis na vida dos Akwẽ. Além disso, Wairê é sempre descrito como preguiçoso; desastrado e imprudente, características contrárias ao ideal de pessoa akwẽ e o que marcaria, a despeito da origem comum, a alteridade do branco em relação aos Akwẽ.

Ainda de acordo com Raposo (2009):

[É] irônico que o mito cristão postule a criação do homem "à imagem e semelhança do Senhor" e que sua versão Akwẽ introduza, sem a menor cerimônia, uma deriva tão drástica rumo a diferença: entre Waptokwa e Pedro, transformada, por sua vez, naquela entre o Akwẽ e o Branco. A versão branca do mito fala da criação como um evento de assemelhamento degenerativo: o homem criado à imagem e semelhança de seu criador, porém decai degenerado. Ao passo que a versão akwẽ trata de um processo de diferenciação geradora de dois tipos distintos de humanos (RAPOSO, 2009, p. 98).

A cosmovisão $a k w \tilde{e}$, por meio das narrativas, remete-nos ainda a uma percepção do socius, enquanto alimentado pelas coisas criadas e deixadas pelos demiurgos e por outras que foram aprendidas ou apreendidas entre povos estrangeiros. Nestes termos, a criatividade não parece residir no interior da socialidade, mas para além de suas fronteiras. No mito acima, a associação dos Akwẽ ao pólo masculino e ao demiurgo inteligente, poderoso e bondoso, deixa subentendido, que a despeito da superioridade 
tecnológica dos brancos ${ }^{11}$, os Akwẽ são mais bem dotados de qualidades (morais, intelectuais e físicas). A superioridade tecnológica dos não-índios não constitui necessariamente um problema, pois o novo foi desde sempre capturado no exterior, ou seja, em espaços e com seres que não participam da socialidade akwẽ. A questão que se coloca é a de descobrir a melhor maneira de lidar com a diferença e de capturar agências exteriores sem ser predado por elas.

Os mitos estão repletos de exemplo da importância e do perigo das relações estabelecidas com inimigos para a sobrevivência e para a reprodução social do grupo. Com diferentes tdekwa (donos), por meio da guerra ou da aliança, os Akwẽ obtiveram muitos dos bens e conhecimentos dos quais dispõem hoje. A história mais célebre é certamente a do roubo do fogo, que entre os Jê foi tirado da onça e permitiu que não mais se comesse alimento cru. Mas, além desta, existem muitas outras narrativas. Assim como a onça era dona do fogo, a batata veio da estrela, o milho do rato, as raízes poderosas do gavião e o inhame do sapo. Portanto, se com inimigo idealmente não se casa, é possível estabelecer com ele outros tipos de troca: rituais, conhecimentos, nomes, prisioneiros etc.

Em trabalho anterior (MELO, 2016), procurei mostrar que a incorporação de coisas, conhecimentos e pessoas buscados para além das fronteiras que delimitam a socialidade akwẽ, fazem parte do ethos do grupo. Argumentei que isso pode ser percebido, dentre outras maneiras, na ênfase na ideia de movimento, muito frequente nos meus dados de campo. Não se trata apenas do movimento do corpo na dança, nos afazeres cotidianos ou nos esportes, mas também dos deslocamentos entre as casas da aldeia, das excursões pelo cerrado, das visitas feitas aos parentes em outras aldeias ou ainda das viagens até as cidades. É comum ouvir: "quem não anda não aprende".

Nestes termos, concordo com Vilaça (2008) que a partir dos Wari, afirma que:

a adoção do cristianismo como algo novo e externo não contradiz a afirmação de continuidade entre essa religião e a cultura nativa, se tomarmos como ponto de partida a premissa básica do interesse deles [dos Wari] e de outros povos ameríndios na captura da perspectiva do outro, seja ele animal, inimigo ou branco. A adoção do ponto de vista dos missionários é mais um movimento nessa direção da captura de uma perspectiva externa (VILAÇA, 2008, p. 117).

Retomemos as narrativas Akwẽ. Como vimos, Waptokwá e Wairê são responsáveis pelas origens, pelo estilo de vida e pelo destino dos Akwẽ. Quando os dois

${ }^{11}$ Resultante da opção feita pelos Akwẽ pelo arco e a flecha quando da divisão das coisas criadas por Waptokwa. 
demiurgos andavam pela terra, eles proviam e protegiam. Mas, eles se mudaram para o céu, e a interposição do mar instaurou uma distância instransponível entre criaturas e criadores. Desde então, as ações de Waptokwá e Wairê são referidas sempre no passado (MATTOS, 2009). Atualmente, a sobrevivência e os infortúnios são atribuídos em grande medida a seres não-humanos que habitam os rios e as matas e com quem os Akwẽ interagem intensamente. Afinal, como gostam de explicar: "o mundo espiritual não é longe, é bem perto!" E se nem todos podem vê-lo, todos com certeza sentem suas influências.

O cosmos é descrito pelos Akwẽ como composto por três níveis: O céu (hêwa), a terra $(t k a)$ e o mundo subterrâneo ( $t k a$ kamô). Cada nível é habitado por subjetividades dotadas de agência e compõe entre si um sistema caracterizado, antes de tudo, pela comunicabilidade. Neste sentido, as histórias contadas dão conta da interação entre corpos celestes e corpos terrestres; entre humanos e não-humanos habitantes dos diferentes níveis e entre seres animados e inanimados. Portanto, mais do que a distância que separa os três níveis do cosmos, o que fica patente nas narrativas é o potencial interativo pautado em transformações.

O sekwa é aquele que entre os Akwẽ é capaz de ver o supra visível e lidar com as agências não humanas. Ele é, portanto, o mediador responsável por garantir que a movimentação do cosmos e a interação entre seus seres aconteçam de maneira adequada. Munidos de seus zã (maracás), os sekwa cantam para curar os doentes, e nas festas $^{12}$ cantam para curar o mundo, ou seja, para mantê-lo longe do caos que a indiferenciação pressupõe. A conexão indevida entre os diferentes níveis e/ou entre os seres que o habitam é causa de doenças e outros infortúnios. As matas, os rios e a aldeia são, portanto, pensados como morada e/ou lugar de trânsito de subjetividades "Outras". Essas subjetividades, ou pelo menos parte delas, aproximam-se do que se convencionou a chamar por espíritos. Entretanto, se na cultura judaico-cristã os espíritos são portadores de uma identidade fixa, as falas cotidianas e as histórias de incursões pelo cerrado e pelos rios, ora nos fazem pensar os espíritos divididos em classes e ora confundindo-se uns com os outros ${ }^{13}$.

\footnotetext{
${ }^{12}$ Segundo Mattos (2009, p. 29), os Akwẽ fazem festa para se sintonizar com a vontade e o legado cultural deixado por $B d \hat{a}$. Por isso quando algum cataclismo acontece os mais velhos costumam atribuí-lo a uma represália do demiurgo pelo fato dos Xerente estarem abandonando o Daĩsipsê.

${ }_{13}$ Viveiros de Castro (2006) nos ajuda a pensar sobre esse aspecto aparentemente antagônico quando explica que as noções geralmente traduzidas por espírito dizem respeito na verdade a uma multiplicidade intensiva, ou seja, "uma região ou momento de indiscernibilidade entre o humano e o não-humano"
} 
Capaz de viajar aos diferentes níveis cósmicos e negociar com subjetividades outras, o sekwa talvez seja aquele que melhor representa a dinâmica necessária entre o interior e o exterior, emergindo, portanto, como uma metáfora da noção akwẽ de movimento e da relação com o Outro.

\section{Xamanismo no contexto da evangelização}

Quando era mais nova, minha maior vontade era ser sekwa. Sekwa para mim era tipo Deus: tinha poder, podia curar as pessoas, saber dos mortos, proteger da chuva, ver coisas que ninguém via. Mas aí eu conheci a palavra e não quis mais não. Hoje eu penso diferente (W. aldeia Salto, setembro de 2015).

Nas festas, portando seus maracás, os sekwa geralmente cantam por longas horas. Seus cantos são sempre povoados pelos seres das matas, dos rios e do céu. Mas eles cantam também para curar os doentes e em outras situações. A palavra cantada, o som do maracá e a pintura corporal são descritos como dotados de potencial conectivo. Eles transportam o xamã para outros lugares e abrem a possibilidade de comunicação com os espíritos. É justamente essa capacidade de comunicação com subjetividades e espaços, a princípio distintos, uma das principais características da atuação dos sekwa entre os Xerente.

Assim, pelo menos no que diz respeito à concepção do xamanismo como um sistema de comunicação e mediação (SZTUTMAN, 2003), a atuação dos sekwa akwẽ não parece se distanciar do xamanismo de outras partes das terras baixas da América do Sul. Também aqui, devido à capacidade de fazer com que os modos de significação de uma realidade reverberem em outra (CUNHA, 1998), o xamã é entendido como um viajante, um “diplomata cósmico" (CASTRO, 2006, p. 310).

Quando cheguei pela primeira vez à aldeia Rio Sono, em março de 2009, lá havia dois sekwa: Srẽnomrĩ e Sikbowẽ, ambos em plena atividade. Extrovertido e sempre muito receptivo, Srẽnomrĩ gostava de contar histórias. Sikbowẽ, por sua vez, era mais introvertido e menos dado a longas conversas. Entretanto, ambos tinham algo em comum: a ênfase nos relatos sobre suas viagens até lugares e pessoas diferentes. Srẽnomrĩ viajou por outros estados e esteve algum tempo entre os Xavante. Sikbowẽ, por sua vez, andou entre os Krahô, Apinajé e entre os Javaé.

(CASTRO, 2006, p. 321). Segundo o autor, os espíritos constituem o testemunho de que nem todas as virtualidades características do continuo mítico foram atualizadas por meio da especiação pós-mítica.

Revista Escritas do Tempo - v. 1, n. 3, nov/2019-fev/2020 - p. 177-200 
Ambos sempre enfatizavam que andar é importante para conhecer outros lugares e pessoas. É fundamental também para aprender. Ouvindo depois sobre as experiências oníricas e sobre a relação estabelecida por eles com os espíritos, passei a ver como o xamã refletia bem o ethos Akwẽ tão pautado no movimento e na incorporação de novos conhecimentos, coisas e pessoas.

Enquanto as experiências oníricas permitem que os sekwa viajem por outros níveis de realidade, a possibilidade e a capacidade do xamã de se comunicar com os espíritos é o que garante a dinâmica correta do cosmo e a sobrevivência dos Akwẽ. O sekwa, assim como se espera dos líderes, se lança ao exterior e negocia com sujeitos outros. A "condição sekwa" é obtida a partir de um vínculo estabelecido com um "espírito" que vai ensinar ao aspirante todo o necessário para fazer dele um xamã. O vínculo com o espírito-mestre e a força do xamã são materializados por pequenas pedras, introduzidas por esse espírito na nuca e em cada uma das articulações do corpo do aprendiz. Nestes termos, o xamã "encorpora" em si a diferença. Seu desafio, de maneira análoga àqueles que se aventuram por terras estrangeiras, é sofrer os inevitáveis efeitos da ação do Outro em si, sem, no entanto, tornase totalmente outro. A condição sekwa habita, nestes termos, na interseção entre o Eu e o Outro, de maneira que o sekwa se torna uma metáfora oportuna para pensarmos o modo como os Akwẽ geralmente se relacionam com o exterior.

A cosmologia xerente é muito marcada pelo receio do fim da humanidade por meio de catástrofes climáticas causadas pela ira celestial. Tanto, que entre os Akwẽ é comum ouvir as pessoas se referindo às festas e grandes rituais como "penitências" (NIMUENDAJÚ, 1942). Nelas, os sekwa sempre assumem um papel importante, seja na orientação da execução dos ritos ou na execução de músicas específicas que se prolongam pela noite, ritmadas pelo maracá.

No passado, como fazem crer as narrativas dos interlocutores de Nimuendajú (1942), os sekwa tinham recursos e capacidade para evitar catástrofes. Ainda hoje eles são tidos como mediadores por excelência nas ocasiões de eclipse, para evitar que a noite fria se instale sobre a terra e, no passado, tinham papel fundamental na cerimônia denominada por Nimuendajú de "grande jejum"14.

Como já mencionado, a redução das atividades bélicas e cerimoniais aliada à ampliação do contato dos com religiosidades cristãs, parece à primeira vista ter relegado

\footnotetext{
${ }^{14}$ De acordo com Nimuendajú (1942, p. 94), o grande jejum (dahẽlwakulkwá), devido à multiplicidade de rituais e porque reunia pessoas de todas as aldeias, era a cerimônia xerente mais importante. Ela era realizada, segundo o autor, quando, em decorrência da raiva do sol, uma estiagem prolongada colocava em risco as colheitas.
} 
o xamanismo a um lugar marginal. Atualmente, a busca pelos sekwa, que acontece sobretudo nos casos de doença, parece se chocar com o princípio cristão de que "só Jesus tem poder e só ele cura". Assim, as acusações de feitiçaria desde sempre presentes entre os Akwẽ hoje também se apoiam em argumentos inspirados na doutrina cristã.

Os espíritos formadores dos sekwa passaram a ser relacionados com hepãrwawe $\tilde{e}^{15}$ (subjetividade tida como chefe dos espíritos e senhor da noite), termo que passou a ser traduzido como diabo. Por isso são comuns falas do tipo: - "sekwa aprende com coisa que não presta. E por isso só faz o mal para as pessoas". Desta maneira, nos contatos iniciais, sobretudo com os ktwanõ (pessoas não indígenas), que são geralmente entendidos como praticantes de alguma religião cristã, dificilmente alguém se admite sekwa, ou declara que recorre às práticas xamânicas em momentos de necessidade.

No que diz respeito ao discurso dos sekwa mais antigos, aos quais não é possível negar o ofício, observa-se, em alguns casos, a utilização de estratégias que visam reelaborar aspectos da formação e/ou da atuação xamânica aproximando-a ao máximo de uma lógica cristã. $\mathrm{O}$ depoimento abaixo, dado por um sekwa, é elucidativo nesse sentido. Nos ajuda a perceber também como os xamãs estão cientes da ambiguidade de sua posição e procuram se esquivar dela:

Pajé é assim, não são todos que aprendem as coisas. Tem pessoas que aprendem coisas que não presta. Eu mesmo aprendi ser sekwa em sonho, sonhando. Waptokwa (Deus) me ensinou sonhando. Novinho! Neste tempo eu tava bem novinho e aprendi em sonho. Eu subi até o céu sonhando. Quando ele me trouxe de volta, só para fazer teste mesmo, botou uma linha fininha, assim, num rio, tipo o mar, e me botou para atravessar em sonho. Me falou: - se você atravessar, você vai aprender muita coisa boa. Eu vou te mostrar. Aí eu atravessei e voltei atravessando e ele disse: - agora vou te ensinar coisas boas. Você vai defender o que é meu filho e tratar os doentes. Se alguma coisa adoece, se adoecer de qualquer coisa. Você vai defender. Só não pode cobrar ninguém. Por isso eu não cobro ninguém. Waptokwa não aceitou. Tem pessoas que estudaram para ser sekwa no mato. Quando espera, aparece coisa que não presta para ele. Eu mesmo não sei dizer. Mas, já ouvi falar que quem aprende com o animal do mato, caça, que a gente chama de hepãrwawẽ também, que é coisa que não presta. Esse faz o mal! Se aprender com o espírito do peixe, é bom. É bom para tratar. Eu mesmo, não aprendi com espírito de bicho nenhum. Foi Waptokwa que me ensinou. Quando acordei eu fui onde ele me ensinou, no mato. Ele já estava lá me esperando. E sem ninguém vê-lo. Eu aprendia só na conversa mesmo. Eu só ouvia a voz. Ele não se mostrou, mas era ele. Se não era Waptokwa, era alguém que ele mandou. Eu aprendi ouvindo. Ele falou: -

\footnotetext{
15 Tudo se passa como se houvesse um gradiente crescente de ambiguidade que começa com os lendários dahaiwakurkwa (os sekwa do sol), passa pelos sekwa que aprendem com o dono dos peixes e culmina com os sekwa que aprendem com os donos de espécies animais.
} 
Agora você vai... Vou te ensinar a cantar primeiro. Vai tratar as pessoas cantando. São três músicas que você vai cantar tratando as pessoas, tratando quem adoece. Foi a primeira coisa que ele ensinou foi a cantar. Eu escutava a voz do maracá batendo na minha cabeça direto. Ele falou: - Agora você faz um maracá. Pega cabaça que vocês têm. Aí eu lembrei do coité, busquei semente de tiririca, daquela mais graúda e fiz do jeito que ele falou. Passei uns três anos aprendendo as coisas que ele ensinava. Até lá não olhei nenhum doente. Ele dizia: - Não vá se mostrar antes de saber tudo! $\left(\mathrm{M}^{16}\right.$, sekwa, $10 \mathrm{de}$ setembro de 2015).

O relato nos remete a um esforço do sekwa, no sentido de destituir sua prática da ambiguidade com que frequentemente são vistos os sekwa. A insistência do ancião em afirmar que seu aprendizado se deu por meio dos sonhos parece querer enfatizar que não houve qualquer contato com o que o ele chamou de espírito do mato ou hepãrwawe (associado ao diabo). Assim, ressaltando que não aprendeu com bicho algum, mas com Deus (Waptokwa), ele explica sua atuação tem como objetivo defender os filhos de Deus, quando doentes.

Outra diferença que ele elenca em relação a sua atuação, quando comparada a de outros, é o fato dele não cobrar pelos atendimentos que faz ${ }^{17}$. Isso refletiria o caráter desinteressado da sua atividade. Ele enfatiza ainda, que se submeteu a uma formação tradicional, sendo apresentado formalmente para as pessoas da aldeia depois de ter passado por todo o processo aprendizado. $\mathrm{O}$ fato de não haver mais a cerimônia que no passado marcava o final da formação xamânica e tornava público quem eram os especialistas, faz aumentar atualmente a desconfiança sobre o que tipo de formação a que os sekwa têm se submetido. Estabelece também a dúvida sobre quem de fato tem conhecimentos xamânicos.

Como mencionado anteriormente, a história dos Akwẽ com a evangelização é antiga. Se a primeira experiência foi com missionários católicos, atualmente a maior influência é protestante. Ao contrário da aldeia Rio Sono, onde cultos e outros eventos evangélicos acontecem apenas de maneira esporádica, a aldeia Salto possui não só uma igreja, como também dirigentes indígenas que são responsáveis pela realização dos cultos.

As aldeias Salto e Porteira, que são próximas, constituem aquelas em que a Missão Batista exerce certamente a maior influência. Com uma atuação entre os Akwẽ

\footnotetext{
${ }^{16}$ Para os Sekwa em atividade e para as pessoas que não se sentiram a vontade de ter os nomes revelados, optei por manter apenas iniciais.

${ }^{17}$ Isso não quer dizer que ele não vá receber pelo serviço prestado, visto que isso já é pressuposto pela regra de reciprocidade. A diferença em relação aos outros sekwa seria, portanto, não estipular um preço, mas deixar a retribuição a critério da família do doente.
} 
que começou de forma esporádica na década de 1930 (GRIGÓRIO, 2014), missionários dessa denominação estabeleceram residência na aldeia Porteira (que é uma das mais antigas). O trabalho de evangelização por eles desenvolvido esteve desde o início pautado na busca pelo entendimento da língua e da cultura akwẽ, de modo a fazer uma tradução da Bíblia que tivesse para os índios o maior sentido possível. Paralelamente, se dedicaram também a projetos de alfabetização, a formação dos primeiros professores indígenas e a produção de material didático na língua materna (idem) ${ }^{18}$.

$\mathrm{Na}$ aldeia Salto, além dos cultos semanais, os próprios índios têm se dedicado a um trabalho de evangelização que envolve a pregação de casa em casa, a apresentação de peças teatrais e as chamadas vigílias. Essas vigílias são reuniões que atravessam noite adentro. Mais do que a pregação da palavra e as orações, a característica principal dessas reuniões noturnas são os cantos e a dança que animam os participantes. Além de atrair novos seguidores, elas têm como objetivo impedir que os convertidos participem de festas em que se faz consumo de bebidas alcoólicas. Por isso mesmo precisam ser animadas e costumam se realizar nas mesmas datas em que se organizam festejos e forrós por diferentes aldeias.

As vigílias se realizam mesmo nas aldeias em que não existem igrejas construídas. Neste caso, podem acontecer em galpões, na parte coberta que geralmente existe no pátio das escolas, ou em alguma casa que comporte os participantes. A atração principal das vigílias é sem dúvida o grupo musical que anima as orações. Como ainda não há muitos músicos akwẽ, o grupo de músicos da aldeia Salto tem se deslocado bastante para animar diferentes eventos. Nessas reuniões, as pessoas, sobretudo os jovens, trajam suas melhores roupas e acessórios. Na aldeia Salto, o anúncio de uma nova vigília sempre era motivo de expectativa ${ }^{19}$.

No início do mês de setembro de 2015 aconteceu na aldeia Porteira um grande culto festivo. Nele os pastores batistas Rinaldo Mattos e Guenter Carlos Krieger, em missão entre os Xerente há mais de cinquenta anos, simbolicamente passaram suas bordunas ${ }^{20}$ para três Akwẽ. Assim, nessa ocasião foram consagrados pastores: Sirnãwẽ da aldeia Salto e Waĩkainẽ e Waĩkazate da aldeia Porteira. Os três trajavam calça jeans e

\footnotetext{
${ }^{18}$ Ainda de acordo com Grigório (2014), o estabelecimento de uma estreita relação entre educação escolar e evangelização é próprio da atuação da missão americana Summer Institute of Linguistics (SIL).

19 Se como explica Schroeder (2006) a relação estabelecida entre aldeias mais novas leva em consideração os agrupamentos originais, fazendo com que as pessoas de aldeias que partilham uma origem comum se reúnam nas festas e casem mais frequentemente entre si, as vigílias têm rompido com essa lógica, fazendo com que grupos de aldeias muito distantes, interajam.

${ }^{20}$ Bastão de Pau-Brasil usado tradicionalmente pelos homens Xerente como símbolo de autoridade. No passado era utilizado também como arma em ocasiões como caçadas e brigas.
} 
estavam sem camisa, de modo a deixar evidente a pintura corporal que identificava o clã ao qual cada um deles pertencia.

Além disso, cada um usava uma "gravata de embira" 21 e carregava a tira colo um patro, ambos tidos como símbolos masculinos de maturidade e sabedoria. Depois de receberem as bordunas e as bênçãos, os novos pastores estenderam suas mãos em direção aos missionários batistas que se colocaram de joelhos diante dos novos pastores. Além de autoridade para o exercício do ofício, a benção dada pelos pastores indígenas aos pastores brancos, parecia querer demonstrar também a então autonomia dos Akwẽ frente ao trabalho de evangelização.

O culto em questão foi realizado ao ar livre sob a sombra de mangueiras frondosas. Contou com a animação musical de músicos akwẽ (teclado, violão e vocal). Compareceram à cerimônia, familiares dos pastores indígenas, pessoas de aldeias circunvizinhas, pastores e missionários batistas de diversas localidades e lideranças religiosas indígenas dos povos Ticuna e Bacairi. Na aldeia Porteira, muitos apenas observaram a cerimônia de longe. No que diz respeito a aldeia Salto, quando se tem vista seu contingente populacional, pode-se dizer que apenas uma pequena parcela da população se deslocou para prestigiar o evento ${ }^{22}$.

Para o missionário batista Rinaldo Mattos, o que possibilita o diálogo entre a cosmologia cristã e a akwẽ, seria, além da analogia entre Deus e Bdã (Waptokwa) enquanto seres criadores, o fato de existir entre os Akwẽ o que o missionário chama de messianismo existencial. Segundo Mattos (2009, p.27), os povos classificados como messiânicos existencialistas seriam caracterizados por uma visão de mundo fatalista, fundamentada na ideia da perda irremediável das condições paradisíacas do tempo mítico. Esses povos seriam contrapostos a outros dotados de um messianismo histórico. Caracterizados por uma postura mais positiva, os povos messiânicos históricos, segundo Mattos, buscam pelos tempos áureos, que embora perdidos, devem se instalar no futuro. Este seria o caso, por exemplo dos Guarani.

O que Mattos (2009) argumenta é que, se por um lado, eventos míticos como o surgimento da morte pela opção feita por Waire ${ }^{23}$ e a separação dos Akwẽ dos seus

\footnotetext{
${ }^{21}$ Cordão curto feito de algodão ou embira e usado bem junto ao pescoço dos anciãos ou dos homens que assumem cargos especiais durante a realização dos rituais. O cordão possui um nó em cada uma das extremidades e uma pena de gavião suspensa voltada para as costas.

${ }^{22} \mathrm{Na}$ semana anterior ao culto de consagração dos pastores indígenas, realizou-se na aldeia Salto, nas águas do rio Tocantins, o batismo de 43 pessoas, entre elas um ancião que também era sekwa.

${ }^{23}$ Uma das narrativas akwẽ conta que no começo do mundo a morte não existia. Um dia quando Bdã e Wairê andavam juntos na terra, à beira de um rio, enquanto observavam as pessoas, começaram a refletir
} 
demiurgos devido a teimosia dos Akwẽ em olharem para trás, são colocados como irreversíveis e aceitos como tal, por outro, as lamentações geralmente expressam aqueles que ouvem tais narrativas denotariam a vontade de que as coisas fossem diferentes. Significariam, portanto, segundo o autor, o desejo pela vida eterna (MATTOS, 2009, p. 39).

Esse desejo, de acordo com o missionário, caracteriza o messianismo existencial e seria o segundo ponto de favorecimento do diálogo entre a cosmologia indígena e a cristã. Entretanto, as percepções de alguns interlocutores e a própria programação evangélica cotidiana da aldeia Salto nos permitem pensar a relação estabelecida com a mensagem do Evangelho sob oura perspectiva.

Wakrãrê, que declarou ser evangélica há muito tempo, explicou que ainda são muitos os Akwe que não acreditam na existência de um Deus. Segundo ela, algumas dessas pessoas alegam que: "o povo que mora embaixo de nós nunca veio visitar a terra, só os Akwẽ já foram lá. Esse povo acredita que aqui exista um Deus e nós sabemos que não tem. Os que não acreditam dizem que nós estamos fazendo a mesma coisa com o céu (Wakrãrê, aldeia Salto, 13 de setembro de 2015)". Sobre a correlação entre Waptokwa e o Deus cristão, Kasumrã, por sua vez, comentou o seguinte:

Waptokwa fez tudo que podia pelos Akwẽ, deu alimento, água, casa, cantos. O resto os Akwẽ têm que resolver por aqui mesmo. Não adianta ficar pedindo coisas para esse Deus. Se alguém, por exemplo, quebrar um osso, mesmo que ore muito, Deus não vai vir colar o osso. Tem que cuidar por aqui mesmo (Kasumrã, adeia Salto, 09 de setembro de 2015).

Mais que a existência ou não de um ser celeste, o que parece estar em jogo é o status desse ser, tal como posto pelo cristianismo. As falas acima e aspectos da cosmovisão akwẽ nos permitem pensar que menos que uma concepção de Deus pautada na ideia de paternidade, a percepção akwẽ de Waptokwa enfatiza a ideia de criação, que é intimamente relacionada a capacidade de prover e de proteger ${ }^{24}$. Não por acaso o título Waptokwa Zawré é atribuído também aos homens que beneficiam de maneira notável os Akwẽ, como Mattos (2009) bem assinala. De maneira análoga, os seres

dizendo "Como iremos fazer, já existem pessoas demais no mundo?! Não vai caber todo mundo!" Pegando um pequeno e leve talo de buriti, Bdã se adiantou, lançou-o na água e vendo-o emergir disse: "É assim que vamos fazer. Nossos filhos vão morrer e depois tornar viver. Wairê discordou alegando que assim as pessoas continuariam aumentando, não haveria caça para todos e as pessoas passariam a comer umas às outras. Wairê lançou então uma pedra na água e vendo que ela afundou sem voltar à superfície, retrucou: "Assim vai ser, as pessoas morrem e não voltam! Então a mãe de Wairê morreu e não voltou. Ele se queixou com Bdã, que respondeu: "Você quis que as coisas fossem assim: Morreu, não volta! Assim será!"”

${ }^{24}$ Tal como quando se fala da figura dos Donos (MELO, 2016). 
celestes ou de outro nível cósmico não têm importância por si só. É a possibilidade de troca, aberta pelo estabelecimento de uma relação com esses seres, que lhes torna alvo de atenção e status especial.

Como vimos, o mar interposto entre os Akwẽ e Waptokwa tornou a convivência com os demiurgos impossível. Desde então, Waptokwa passou a ser muito mais do que um Ser que corrige, do que como alguém que cuida e provê. Tendo em vista que entre os Akwẽ, a exemplo de outros povos indígenas, as relações de parentesco implicam convivência próxima e trocas recíprocas ${ }^{25}$, com a interposição do mar é como se a relação com os demiurgos tivesse passado do parentesco à afinidade.

O que quero argumentar, a partir da fala de Kasumrã registrada, é que não parece fazer sentido solicitar nada a um Deus que está tão distante. Portanto, se os lamentos diante da postura de Waire e dos próprios Akwẽ nos eventos míticos expressam de fato o desejo que as coisas tivessem acontecido de maneira diferente, não necessariamente significam a crença que elas serão, por meio da veiculação do evangelho e de um investimento na figura do Deus cristão. Ganha destaque, neste sentido, a escassez de formulações akwẽ sobre o céu e sobre a vida após a morte.

Assim, em meio a imagem de dois seres celestes (Bdã e Cristo), a relação dos Akwẽ com a evangelização, mais do que numa preocupação com uma vida eterna, parece estar pautada no interesse de ter atendidas necessidades mais imediatas, como cura e proteção. Coisas que antes só eram possíveis por meio dos sekwa. Para tanto, por meio da oração e da música, procura-se estreitar os vínculos com o deus poderoso dos brancos. A conversão permitiria, nestes termos, o acesso a atributos dos xamãs. Se antes os sekwa eram símbolos por excelência desse poder de barganha junto a subjetividades não-humanas, a possibilidade de comunicação direta com o ser celeste faz com que o cristianismo, neste aspecto, torne todo mundo um pouco sekwa.

A possibilidade de barganha com subjetividades consideradas poderosas faz sentido também, quando temos em vista que o acervo de narrativas míticas é permeado por histórias de catástrofes que colocam em risco a humanidade. Portanto, ao contrário da ideia de "messianismo existencial" enfatizada por Mattos (2009), acredito que a adesão dos Akwẽ ao cristianismo tem mais a ver com que Vilaça (2008) aponta para o contexto Wari: que a adesão ao cristianismo parece ser menos motivo de tormento

${ }^{25}$ Ver: Vilaça (2002), Fausto (2002). 
moral, que de uma busca de solução para um tormento já existente causado pela questão da frágil humanidade ${ }^{26}$.

Entretanto, se a conversão, por um lado, acarreta a diminuição do prestígio dos xamãs, por outro, eles continuam sendo considerados os especialistas por excelência no sobrenatural, porque continuam sendo os únicos capazes de se comunicar com a figura dos Donos. A existência e a influência destes, independente de consideradas boas ou ruins, não são questionadas. Desse modo, também os crentes recorrem aos sekwa nos casos de doença mais graves.

Os relatos fazem crer que, no que diz respeito ao processo de evangelização, há momentos de maior efervescência alternados com outros em que parece haver um arrefecimento da busca pelo evangelho. Mas em todos eles os Xerente parecem praticar a fé cristã dentro de uma lógica muito própria que em muitos pontos nos remete a uma maneira xamânica de pensar a realidade.

O processo de conversão tornou possível também o acesso a relatos dos chamados ex-sekwa ou sekwa convertidos. Além de um xamã que foi batizado em uma cerimônia coletiva realizada por pastores Batista na aldeia Salto em 2015, ouvi o relato de conversão de Srẽnomrĩ, sekwa que conheci quando visitei a aldeia Rio Sono em 2009. Ouvi falar ainda um terceiro sekwa que teria se tornado evangélico. Este último, segundo Srẽnomrĩ, teria feito de sua conversão uma estratégia para tornar sua vida mais longa, pois através da adesão ao cristianismo o sekwa teria buscado desfazer acordo previamente estabelecido com seu espírito-mestre. Essa explicação dada por Srẽnomrĩ nos é elucidativa. Pois, se a conversão pode ser pensada como meio de estabelecer uma aliança com outra força sobrenatural que se espera superior, com o objetivo de obter proteção, poder e outras vantagens, podemos dizer que ela não rompe com a lógica tradicional dos Akwẽ de se relacionarem com o sobrenatural.

Em 2015, Srẽnomrĩ havia se mudado da aldeia Rio Sono para a cidade de Tocantínia. Lá frequentava regularmente uma igreja evangélica e costumava acompanhar missionários nos cultos realizados nas aldeias. No mês de setembro do mesmo ano, Srẽnomrĩ esteve presente em um culto realizado numa noite de domingo na

\footnotetext{
${ }^{26}$ As reflexões que se ouvem na aldeia sobre notícias veiculadas na mídia acerca do aquecimento global, de enchentes e de terremotos, geralmente são comentadas tendo como base a percepção dos fenômenos naturais como resposta da ira celeste diante das atitudes dos homens. Uma das explicações que escutei para o terremoto e o tsunami que atingiram simultaneamente o Japão no ano de 2011, por exemplo, foi que isso teria acontecido devido ao fato dos japoneses quererem se igualar a Deus criando a vida a partir de robôs.
} 
aldeia Salto. Levou consigo uma sanfona que ganhou de presente de um pastor e, além de cantar algumas músicas compostas por ele mesmo, falou de sua conversão.

Como nessa ocasião estavam presentes também pastores batistas de Tocantínia, autodeclarando-se como ex-sekwa, explicou em português: “- Eu era feiticeiro. Quando me zangava com alguém, pensava: vou jogar feitiço mesmo!" Enquanto a assembleia se divertia com o relato, Srẽnomrĩ completou: "-Mas o Jesus me salvou quando o diabo vinha me buscar. Agora eu rezo com o Espírito Santo e canto para falar de Jesus". Uma das composições de Srẽnomrĩ cantadas por ele nessa ocasião foi a seguinte:

\section{Hêsuka sikwasari}

Hêsuka sikwasari, bato wê ĩ kamõi nĩ (2x)

Amã krĩnĩ harâ mnõ da, azô inmmĩ sinã (2x)

Srênõmri sĩ hrâwẽ zawre di, Waptokwa Zawre damã sĩ hrâ wa,

Wazatô tônmẽ krĩnĩ hârâ, azô inmmĩ sinã.

\section{(Versão em Português):}

Jesus Cristo me deu essa sanfona

Para tocar para Jesus Cristo

Srẽnomrĩ toca bonito demais quando está tocando para Jesus Cristo

Eu vou tocando esperando Jesus Cristo

Quando ele vier me buscar eu vou para o céu, eu vou para o céu,

Lá no céu eu vou morar mais Jesus Cristo.

Sobre Srẽnomrĩ, que era também evangélico, meu anfitrião na aldeia Salto, contou que quando sua filha mais nova, que tinha apenas um ano e quatro meses, passou a padecer com uma ferida na boca que não cicatrizava, Srênõmiri, ao vê-la ao final de um culto, disse que ela estava doente por obra do diabo. Então soprou/sugou a boca da criança e disse que ela ficaria boa. O pai da criança disse ter ficado intrigado, pois mesmo tendo convicção que Srênõmiri estava convertido e pregava a palavra, sabia que aquele era o jeito dos sekwa olharem as pessoas.

Não apenas a forma de Srẽnomrĩ interceder pela criança lembrou aspectos do xamanismo, pontos da música composta por ele e mesmo a percepção de que reza pelas pessoas orientado pelo Espírito Santo, remete-nos a uma lógica análoga aquela que fundamenta a relação do sekwa com seu espírito-mestre. O sekwa não tem poder por si mesmo. $\mathrm{O}$ que cura é a força de seu espírito-mestre transmitida aos enfermos por meio do sopro do sekwa. Por outro lado, a música de Srênõmiri enfatiza algo que lhe foi dado pelo mestre para que ele trabalhe pelas pessoas, evangelizando-as. Nestes termos, poderíamos pensar a sanfona como análoga ao maracá ou aos itens que compõem o ĩsimro (equipamento xamânico dado pelo espírito mestre). A música de Srênõmiri 
menciona ainda sua morada futura, ao lado do Jesus que virá buscá-lo, tal como fazem os espíritos-mestre com seus iniciados.

Para além da canção de Srênõmiri, de maneira semelhante ao que observamos no xamanismo xerente, a música é certamente algo marcante nas diferentes celebrações evangélicas que acontecem na aldeia ${ }^{27}$. Aliás, no cotidiano de boa parte das aldeias que tive oportunidade de conhecer. Assim, na aldeia Salto, a exemplo de outras, as pessoas apreciam muito escutar música em alto volume, de modo que não é difícil perceber o gosto musical dos moradores, mesmo daqueles que moram mais distante. O forró parece ser um dos gêneros mais apreciados e também as músicas evangélicas, em alguns casos, são tocadas neste ritmo.

A igreja da aldeia Salto possui uma caixa amplificada, microfones e um grupo musical composto por um tecladista, um violonista e dois vocalistas. Todos os componentes do grupo são akwẽ. Mesmo que nos cultos semanais o grupo nem sempre se apresente completo, pelo menos o tecladista comparece para tocar algumas músicas para animar as celebrações. Uma ou duas horas antes do início do culto, ele organiza o som e deixa o microfone disponível para quem quiser ensaiar canções para serem cantadas durante a celebração.

Assim, por algum tempo antes da celebração é possível perceber a movimentação de jovens e crianças na igreja e ouvi-las cantar animadamente. Músicas evangélicas em português e em akwẽ compõem o repertório. Os "calouros" se divertem, mas não escondem certo constrangimento quando erram a letra ou o ritmo das canções. Para se encorajarem às vezes preferem cantar em dupla ou em trio.

Durante o culto, entre os momentos de oração e de pregação da palavra, que são relativamente rápidos, várias vezes o microfone é disponibilizado para aqueles que estão dispostos a cantar alguma canção. Essa ocasião parece ser esperada com expectativa tanto pelos que se prepararam para cantar, quanto pelos demais. A maior parte das músicas escolhidas é cantada em akwẽ e em alguns casos são composições dos próprios índios. Os números apresentados são ouvidos com atenção. Quando se trata de músicas conhecidas, a assembleia canta junto.

\footnotetext{
${ }^{27}$ Capiberibe (2017) relata que entre os Palikur "Nos cultos, vê-se que os jovens estão voltando as costas para 'as palavras' e, ao mesmo tempo, lançando-se com energia e fúria para dois outros aspectos da liturgia do ritual, a entoação de músicas e as danças que as acompanham, que estão diretamente relacionados ao transe religioso, o que é visto pelos mais velhos como 'desrespeito' em relação aos pastores e mesmo a Deus" (CAPIBERIBE, 2017, p. 321).
} 
Certo dia, um ancião, enquanto observávamos o movimento das pessoas que cruzavam o pátio escuro da aldeia se dirigindo para o culto, comentou comigo que lamentava o interesse tão grande pelo cristianismo. Segundo ele, muitos hoje já valorizavam mais as celebrações religiosas do que a "festa da cultura". Reclamou também que muitas crianças conheciam mais músicas religiosas do que músicas akwẽ.

Por ironia, paralelamente ao forte movimento de evangelização, a aldeia Salto é uma das mais efervescentes no que diz respeito à realização do dasĩpse, que é hoje a festa Xerente mais importante. Enquanto a aldeia Rio Sono não realiza um há mais de dez anos, e outras aldeias organizam de maneira esporádica, em 2015 fazia pelo menos cinco anos, que a aldeia Salto realizava essa festa de maneira ininterrupta, geralmente no mês de julho. Tem havido uma grande preocupação de pesquisar junto aos mais velhos sobre a transmissão dos nomes de acordo com os clãs, sobre a correta realização das corridas de tora e outras competições e outros aspectos, para que a festa se aproxime o máximo possível dos moldes tidos como tradicionais ${ }^{28}$.

O pastor akwẽ responsável pela igreja da aldeia, de posse do seu maracá é também quem canta e anima com músicas $a k w e \tilde{e}$ as danças que acontecem no pátio em muitos momentos durante os dias festivos. O ancião mencionado anteriormente, reclamou que boa parte dessas canções cantadas no pátio, são músicas que antes eram cantadas apenas pelos sekwa. Segundo ele, hoje elas estariam sendo cantadas sem critério pelos mais jovens.

Tradicionalmente, o acervo musical é composto por músicas deixadas pelos demiurgos, como é o caso das músicas entoadas durante a nominação das meninas, algumas cantigas de pátio e pelas canções de pátio dos sekwa. Para além de canções de pátio, cada xamã possui ainda uma canção que lhe é dada/ensinada pelo seu espíritomestre e que não deve ser entoada por outra pessoa. Os sekwa são, portanto, os únicos entendidos como donos de canções.

A música, devido sua capacidade de propiciar momentos de interação entre as pessoas e de conectar níveis de realidade distintos tem papel central nas festas e nas sessões xamânicas. Não parece estranho, portanto, que nas celebrações evangélicas ela pareça constituir o ápice e aquilo que torna tanto os cultos quanto as viǵ́lias eventos atrativos. As vigílias, por exemplo, seguem uma lógica que, de alguma maneira, remete às noites em que os sekwa cantavam noite adentro enquanto as pessoas dançavam. Além

${ }^{28} \mathrm{Na}$ festa de 2015, por exemplo, todas as pessoas, inclusive as crianças, para receberem a comida distribuída durante a festa precisavam ter siktõ (cesto trançado com palha de buriti).

Revista Escritas do Tempo - v. 1, n. 3, nov/2019-fev/2020 - p. 177-200 
disso, a percepção da possibilidade de obter curas a partir da oração, o interesse das pessoas em interpretarem e comporem canções falando de e com Deus, permite-nos pensar a prática do cristianismo como um meio de democratização de atributos antes só possíveis aos xamãs.

Para pensar, portanto, os sekwa no contexto da adesão dos Xerente ao cristianismo é preciso ter em vista que o xamanismo, como bem nos lembra Chaumeil (2000), possui um caráter não-dogmático que lhe confere uma notável capacidade de agregação de elementos provindos do exterior. Até mesmo porque a interação/mediação com o exterior é a essência do xamanismo. Nesta perspectiva, assim como os donos das espécies naturais, também outros povos indígenas e os brancos constituem figuras de alteridade e como tal são fonte de poder xamânico.

Por isso, somos levados a pensar que se por um lado o fortalecimento do cristianismo exerce certa censura sobre os xamãs e aqueles que recorrem as suas práticas, por outro, o xamanismo parece estar diluído e operante não apenas no modo $a k w \tilde{e}$ de se apropriar do cristianismo, mas, de maneira mais ampla, no modo dos Akwẽ de fazer política com o exterior e de entender e experimentar o mundo.

\section{Referências}

CAPIBERIBE, Artionka. A língua franca do suprassensível: sobre xamanismo, cristianismo e transformação. Mana, v.23, n.2, p.311-340, 2017.

CARNEIRO DA CUNHA, M. Pontos de vista sobre a floresta amazônica: xamanismo e tradução. Mana, v. 4, n. 1, p. 7-22, 1998.

CHAUMEIL, Jean-Pierre. Voir, savoir, pouvoir. Le chamanisme chez les yagua de 1'Amazonie péruvienne. Genève: Georg. Collection Ethnos, 2000.

COELHO DE SOUZA, Marcela.S. O Traço e o Círculo: o conceito de parentesco entre os Jê e seus antropólogos. Tese (Doutorado em Antropologia), Museu Nacional/ Universidade Federal do Rio de Janeiro, Rio de Janeiro, 2002.

EWART, Elizabeth. Space and Society in Central Brazil: A Panará Ethnography, London School of Economics Monographs on Social Anthropology. Bloomsbury Academic: London, 2013.

FAUSTO, Carlos. Banquete de gente: comensalidade e canibalismo na Amazônia. Mana, v.8, n.2, p.744-772, 2002.

GALLOIS, Dominique. Xamanismo Waiãpi: nos caminhos invisíveis, a relação i-paie. In: 
LANGDON, E. J. (Org.). Xamanismo no Brasil: novas perspectivas. Florianópolis: Ed. da UFSC, 1996.

GIRALDIN, Odair. Pontal e Porto Real. Dois arraiais do norte de Goiás e os conflitos com os Xerente nos séculos XVIII e XIX. Revista Amazonense de História, v. 1, p. 131$146,2002$.

Povos indígenas e não-indígenas: uma introdução à história das relações interétnicas no Tocantins. In: GIRALDIN, Odair (Org.). A (trans)formação histórica do Tocantins. Palmas: Unitins-Goiânia: CEGRAF, 2004.

GIRALDIN, Odair; SILVA, Cleuber Alves da. Ligando Mundos: relação entre xerentee a sociedade circundante no século XIX. Boletim do Museu Paraense Emílio Goeldi. Belém, 2002. (Série Antropologia).

GORDON, César. Economia Selvagem. São Paulo: Unesp, ISA/NuTI, 2006.

GRIGÓRIO, P. C. O. "Evangelho não destrói culturas”. A Missão Transcultural Batista entre os índios Xerente do Tocantins. In. XVI ENCONTRO REGIONAL DE HISTÓRIA DA ANPHU-RIO: saberes e práticas científicas. Rio de Janeiro, RJ, 2014.

LANGDON, E. J. Introdução: Xamanismo - velhas e novas perspectivas. In: LANGDON, E. J. (Org.). Xamanismo no Brasil: novas perspectivas. Florianópolis: Ed. da UFSC, 1996.

MATTOS, Rinaldo de. O messianismo existencial Xerente. Revista Antropos, v. 3, n. 2, p.2738, 2009.

MAYBURY-LEWIS, D. [1965]. O selvagem e o inocente. Campinas: Ed. UNICAMP, 1990.

MELO, Valéria M. C. O movimento do mundo. Cosmologia, alteração e xamanismo entre os Akwẽ-Xerente. Tese (Doutorado em Antropologia Social), Universidade Federal do Amazonas, Manaus, AM, 2016.

MORAIS-NETO, Odilon. Sawrepté: imagens do Brasil Central. Dissertação (Mestrado em Antropologia Social), Universidade de Brasília, Brasília, 2007.

NIMUENDAJÚ, Curt. The Serente. Los Angeles. The Southwest Museum, 1942.

PÉREZ-GIL, Laura. Transformação do xamanismo e sociabilidade entre os yaminawa. In. XXVIII REUNIÃO DA ASSOCIAÇÃO BRASILEIRA DE PÓS-GRADUAÇÃO E PESQUISA EM CIÊNCIAS SOCIAIS (ANPOCS). Caxambu, MG, 2004.

PISSOLATO, Elizabeth. A noção de transformação entre os Jê. Dissertação (Mestrado em Antropologia Social), Museu Nacional/ Universidade Federal do Rio de Janeiro Rio de Janeiro, RJ, 1996. 
RAPOSO, Clarisse M. dos A. Produzindo diferença: gênero, dualismo e transformação entre os Akwe-Xerente. Dissertação (Mestrado em Antropologia Social), Universidade Federal de Minas Gerais, Belo Horizonte, MG, 2009.

SCHROEDER, Ivo. Política e parentesco nos Xerente. Tese (Doutorado em Antropologia Social), Universidade de São Paulo, São Paulo, SP, 2006.

SZTUTMAN, Renato. Comunicações alteradas: festa e xamanismo na Guiana. Campos, Curitiba, v.4, 2003.

VILAÇA, Aparecida. O que significa tornar-se outro? Xamanismo e contato interétnico na Amazônia. Revista Brasileira de Ciências Sociais, vol.15, n.44, p.56-72, 2000.

Aparecida. Making kin out of others in Amazoniall. Journal of the Royal Anthropological Institute, n.82, pp. 347-365, 2002.

Conversão, Predação e Perspectiva. Mana, v.14, n.1, p.173-204, 2008.

VIVEIROS DE CASTRO, Eduardo. Araweté: os deuses canibais. Rio de Janeiro: Zahar/ANPOCS, 1986.

O mármore e a murta: sobre a inconstância da alma selvagem. Revista de Antropologia. São Paulo, USP, v. 35, p. 21-74, 1992.

A floresta de cristal. Notas sobre a ontologia dos espíritos amazônicos.

Cadernos de campo, São Paulo: Universidade de São Paulo. n. 14/15, p. 319-338, 2006.

Artigo submetido em 15 de janeiro de 2020. Aprovado em 28 de fevereiro de 2020. 